\title{
Turismo e Desenvolvimento - Desafios à Comunicação Intercultural
}

https://doi.org/10.21814/uminho.ed.48.9

Lurdes Macedo

Centro de Estudos de Comunicação e Sociedade, Instituto de Ciências Sociais, Universidade do Minho, Braga, Portugal http://orcid.org/0000-0002-1577-1313

mlmacedo71@gmail.com

\section{Resumo}

De acordo com Duarte (2016), os discursos político e mediático associam o fenómeno do turismo ao facto de os cidadãos viajarem, independentemente do que eles vão fazer no destino para onde se deslocam e dos objetivos que pretendem alcançar. Portanto, deveremos questionar essa associação pela confusão que suscita, a partir da premissa de que imergir num outro mundo que não o nosso não corresponde linearmente à participação na indústria capitalista do turismo. Para tornar apetecível o conjunto de bens e de serviços com que organizam a sua oferta, os promotores da indústria turística operam modificações estratégicas no tecido do território, formatando os lugares e as suas gentes de acordo com as exigências da procura turística. É a partir desta dinâmica que inquiriremos a relação entre turismo e desenvolvimento, convocando os desafios que tal inquirição coloca à comunicação intercultural. Sugerem-se algumas pistas para ultrapassar as contradições entre turismo e desenvolvimento, sobretudo, a partir das possibilidades que nos são oferecidas pelas metodologias participativas e ativas. Daqui decorre uma conclusão que parece ser inevitável: mais do que promover as condições e de reunir os meios para o aumento da riqueza, o desenvolvimento deverá ser um debate amplamente participado sobre o futuro das sociedades.

\section{Palavras-chave}

turismo, desenvolvimento, comunicação intercultural 


\section{Sobre o Turismo}

Na sua "Introdução a uma crítica radical do turismo", publicada no jornal Mapa, a 7 de abril de 2016, P. Duarte propõe uma distinção, sem dúvida pertinente, entre fazer turismo e viajar. No entendimento do autor, os discursos político e mediático tendem a associar o fenómeno do turismo ao facto de as pessoas viajarem, independentemente do que elas vão fazer no destino para onde se deslocam. Assim, e no dizer do próprio autor, "instalou-se a ideia de que viajar e fazer turismo seriam sinónimos" (para. 2).

Contudo, deveremos questionar essa confusão a partir de uma premissa: imergir num outro mundo que não é o nosso, o que é quase sempre uma experiência enriquecedora e até transformadora, não corresponde exatamente à participação na indústria capitalista do turismo. Aliás, P. Duarte (2016) define o turismo "como a indústria que manipula as materialidades de que é composto o território para aí fabricar imagens e experiências vendáveis àqueles que viajam" (para. 4). 0 autor prossegue a sua reflexão enfatizando que, sob a lógica do turismo, patrimónios e identidades são não só recuperados - o que, em teoria, constituiria uma das suas consequências positivas ${ }^{1}$ - como também "inventados de raiz", a fim de ser criada uma oferta diversificada de produtos e serviços nivelados "pela sua capacidade para atrair e seduzir aqueles que viajam" (Duarte, 2016, para. 4). Com isto, o autor conclui que o turismo - denominado como uma "indústria" no nosso tempo - não é mais do que o modo de viajar próprio do capitalismo.

Assim, para tornarem apetecível o conjunto de bens e de serviços com que organizam a sua oferta, os promotores da indústria turística operam modificações estratégicas no tecido do território, formatando os lugares e até as suas gentes de acordo com as exigências da procura turística. É deste modo que se produzem transformações profundas tanto no património histórico, como nas paisagens e nos hábitos que marcam a cultura e a identidade das comunidades que habitam esses lugares. Em territórios convertidos em destino turístico, os habitantes testemunham assim, no seu quotidiano, a concretização de uma das leis fundamentais da sociedade do espetáculo, ao verem aquilo que era vivido transformar-se numa representação.

Estas transformações produzem, naturalmente, inúmeros efeitos colaterais sobre os quais raramente se considera relevante discutir, sobretudo nas esferas política e mediática. Por isso mesmo, encontros científicos com o fim de inquirir as relações entre turismo, desenvolvimento e promoção da paz, como aquele que se realizou em Maputo, em novembro de 2018, configuram-se como espaços de reflexão crítica necessários para se pensar o turismo na sua relação complexa com o desenvolvimento.

É certo que, para dar início a esta curta reflexão, se recorreu a uma crítica que se intitula a si própria de radical, por sua vez publicada num jornal de informação crítica; mas talvez seja esta a abordagem mais útil se quisermos refletir sobre a relação entre turismo e desenvolvimento, sobretudo, se a situarmos em territórios onde 
ambos os fatores da equação se encontram ainda bem distantes de esgotar todo o seu potencial. Sublinhe-se que é precisamente nestes territórios, em que o binómio turismo/desenvolvimento é ainda passível de uma gestão cuidada e sustentável, que as possibilidades de evitar os problemas identificados nos lugares transformados pelo turismo são reais e, de igual modo, desejáveis.

\section{Sobre o Desenvolvimento}

Pelo seu lado, o desenvolvimento, longe de constituir um conceito neutro ou de suscitar consenso, é assumido como preocupação coletiva, ficando a cargo dos Estados e das organizações internacionais a definição das políticas e das estratégias para a sua promoção. Nos mais diversos pontos do mundo, estes atores parecem empenhados em diligenciar as condições e em reunir os meios necessários para produzir um aumento da riqueza, enquadrando este esforço nas dinâmicas do sistema capitalista. Todavia, e talvez por isso mesmo, nem sempre o bem-estar das populações é tido em conta como fator nesta equação. Daqui é possível concluir que tanto o turismo como o desenvolvimento não podem ser pensados de forma indissociável do sistema capitalista global.

Contudo, e como bem observa Ribeiro (2018), o desenvolvimento é ainda uma miragem para muitos povos, para muitos países e também para muitas camadas sociais. Apesar do investimento em consecutivos planos de desenvolvimento, os objetivos definidos para os mesmos continuam a focar-se em necessidades tão básicas como a eliminação da fome ou da pobreza. O mesmo autor adverte, logo de seguida, para o facto de o desenvolvimento, mesmo na sua formulação "sustentável", não ter sido ainda capaz de dar resposta adequada aos problemas provocados pelo capitalismo, como, por exemplo, o esgotamento dos recursos naturais ou as alterações climáticas.

Desta forma, o desafio que nos é colocado, quando pensamos no desenvolvimento que se deseja para um mundo idealmente sustentável, parece configurar uma missão quase impossível: compatibilizar o bem-estar das sociedades humanas com as possibilidades ecológicas do planeta e, ao mesmo tempo, promover uma efetiva redução das desigualdades.

O debate em torno deste desafio ganharia outra amplitude se as diversas centralidades analíticas que produz - e que se apresentam sob o espectro da fragmentação - fossem vistas, ao invés, de forma integrada. Na realidade, estas centralidades analíticas acabam por se excluir mutuamente, fazendo tardar a resolução dos problemas dos países em desenvolvimento, num mundo cada vez mais global e interdependente. Para este estado de coisas poderão ser apontadas duas razões de fundo: por um lado, o peso das fronteiras científicas e das diferentes tradições disciplinares que concorrem neste debate; por outro, o facto de o mundo complexo que hoje nos é apresentado resultar de um longo processo de colonialismo europeu que, quer seja historiado pelo ex-colonizador, quer seja historiado pelo ex-colonizado, nunca poderá constituir uma história edificante, tal como enfatizou Said (1993/2011). 


\section{Turismo e Desenvolvimento Sob a Ótica da Comunicação Intercultural}

É neste quadro de fragmentação e de pós-colonialidade do debate sobre o futuro do desenvolvimento que a comunicação intercultural pode exercer um papel diferenciador, conduzindo a reflexões aprofundadas numa lógica transdisciplinar. Tal como a entendem Cabecinhas e Cunha (2008), a comunicação intercultural acolhe as diversas leituras despoletadas pelas múltiplas dinâmicas de relação entre pessoas, bens e ideias. A partir desta perspetiva, é possível dar forma a uma narrativa crítica capaz de dar conta de realidades processuais em que se cruzam participantes de várias etnias, religiões e culturas, sem esquecer as condições de desigualdade com que estes interagem, as fronteiras que entre eles se interpõem e, finalmente, a enorme distância que separa as suas inter-relações reais de uma eventual convergência de interesses. Será então a partir da perspetiva da comunicação intercultural que se apresentarão adiante algumas pistas para a reflexão sobre a relação entre turismo e desenvolvimento.

E porque é no quadro do capitalismo que devemos equacionar este binómio, comecemos por questionar a comunicação intercultural, ou a falta das funções que esta poderia exercer, ao nível da criação de valor em projetos de planeamento estratégico para o desenvolvimento. Tome-se por exemplo a comunicação destinada a tornar um território mais competitivo, com o objetivo de atrair investidores, eventos e turistas. A experiência dos profissionais dedicados a esta área tem revelado que tal comunicação só é eficaz quando, para além da identificação das parcerias e dos destinatários das diversas ações, são escolhidas as formas mais adequadas para promover a sua adesão e capacitação, bem como a assunção de compromissos para o futuro. Qualquer plano estratégico de desenvolvimento, que implica normalmente uma operacionalização baseada na cooperação interinstitucional e no envolvimento das comunidades, deve refletir sobre os meios a adotar para garantir uma comunicação efetiva, fazendo-a perdurar por períodos temporais adequados, ou seja, não se limitando à comunicação de processo. Esta comunicação começa a construir-se durante a fase de planeamento, suportando-se nele e acrescentando-lhe informação relevante, a partir da criação de plataformas de concertação e de mecanismos de monitorização e de avaliação abrangentes, que atendem quer às realizações (na ótica de quem implementa), quer aos resultados e aos impactos (na ótica dos destinatários).

Sem a participação efetiva das comunidades que habitam os territórios onde o desenvolvimento é induzido pelo turismo, não é possível planear, operacionalizar e obter resultados ao nível da sustentabilidade e do bem-estar de todos os atores desta relação. Veja-se, a título de exemplo, o que se passa com alguns processos de patrimonialização, em que as comunidades se revoltam por se sentirem espoliadas de bens que originalmente eram só seus. Portanto, a proposta é a de pensarmos a comunicação intercultural assente na eficácia, o que remete para a utilização de metodologias participativas. 
Valerá então a pena questionar as funções sociais da comunicação em projectos de desenvolvimento, nomeadamente aqueles que aqui interessa analisar, ou seja, os que promovem o desenvolvimento por via da indução do turismo. Podendo ser utilizada a diversos níveis nestes contextos, a comunicação é tida em conta, a maior parte das vezes, mais pela sua natureza instrumental do que pela sua natureza transformadora face aos processos de intervenção e aos objetivos de mudança. 0 mesmo é dizer que os efeitos da persuasão são largamente mais explorados do que as virtudes da capacitação, quando se intervém em comunicação para o desenvolvimento. Com efeito, tanto a norte quanto a sul, são privilegiadas grandes campanhas de comunicação persuasiva sobretudo junto a comunidades tradicionais ou excluídas dos circuitos de comunicação e de poder, com vista à sua mudança comportamental, em detrimento da utilização de técnicas participativas capazes de envolver e de comprometer essas comunidades na construção do seu próprio futuro. Portanto, uma outra proposta para pensarmos a comunicação intercultural é a de a basearmos na capacitação, o que remete para a utilização de pedagogias ativas.

Deste curto exercício de reflexão e de questionamento resulta uma ideia que parece ser central para o futuro do debate que aqui nos mobiliza: mais do que promover as condições e reunir os meios para o aumento da riqueza, por exemplo, por via da intensificação do turismo de massas, atividade na qual o grosso do capital gerado está muito longe de ser distribuído equitativamente pelas populações residentes, o desenvolvimento deverá ser, antes de mais, um debate amplamente participado sobre o futuro das sociedades.

\section{Agradecimentos}

Este trabalho é financiado por fundos nacionais através da FCT - Fundação para a Ciência e a Tecnologia, I.P., no âmbito do projeto UIDB/00736/2020. É também apoiado no âmbito da "Knowledge for Development Initiative", pela Rede Aga Khan para o Desenvolvimento e pela FCT - Fundação para a Ciência e Tecnologia, IP (n. ${ }^{\circ}$ 333162622) no contexto do projeto Memories, cultures and identities: how the past weights on the present-day intercultural relations in Mozambique and Portugal?

\section{Referências}

Cabecinhas, R., \& Cunha, L. (2008). Introdução. Da importância do diálogo ao desafio da interculturalidade. In R. Cabecinhas \& L. Cunha(Eds.), Comunicação intercultural. Perspetivas, dilemas e desafios(pp. 7-12). Campo das Letras.

Duarte, P. (2016, 7 de abril). Introdução a uma crítica radical do turismo. Mapa. http://www.jornalmapa. pt/2016/04/07/introducao-a-uma-critica-radical-do-turismo/

Ribeiro, F. B. (2018). Uma sociologia do desenvolvimento. Húmus.

Said, E. (2011). Cultura e imperialismo (D. Bottman, Trad.). Companhia das Letras. (Trabalho original publicado em 1993) 